\title{
Afinal, queremos ou não viabilizar o uso agrícola do lodo produzido em estações de esgoto sanitário? Uma avaliação crítica da Resolução CONAMA 375
}

\section{Américo de Oliveira Sampaio*}

\section{Introdução}

Os processos de tratamento de esgotos sanitários geram resíduos sólidos, cujas características quali-quantitativas podem variar substancialmente, dependendo de uma série de fatores, dentre os quais se pode destacar: os tipos de processos e operações constituintes do tratamento, a quantidade e características dos efluentes não domésticos lançados no sistema coletor de esgotos e o tipo de condicionamento e desaguamento do lodo utilizado na fase sólida do tratamento.

Estima-se que os custos operacionais associados apenas à destinação final deste material contribuam com mais de $40 \%$ do montante total (SAMPAIO; GONÇALVES, 1999). Apesar de sua importância, os aspectos relacionados ao gerenciamento do lodo de ETEs não vêm recebendo a necessária consideração por parte das instituições e profissionais responsáveis por essa questão. Os que há muito militam nessa área sabem bem que, até pouco tempo atrás, nos projetos hidráulico e sanitário de estações de tratamento de esgoto a preocupação com o lodo se limitava à apresentação de figuras de um caminhão e uma seta, acompanhada pelos dizeres: "VAI PARA DESTINO FINAL".

No Brasil, a grande maioria das estações atualmente em operação envia o lodo gerado para aterro sanitário. Apenas algumas encaminham esse material para uso agrícola, muito embora tal destinação venha crescendo consideravelmente nos últimos anos, principalmente nos Estados do Paraná, São Paulo, Rio Grande do Sul e Distrito Federal. Estima-se que a quantidade atual de lodo utilizada para este fim no Brasil seja da ordem de 21.000 toneladas (base seca) /mês, sendo produzida, em sua quase totalidade, em estações que utilizam processos de tratamento biológicos aeróbios (lodos ativados convencional ou aeração prolongada e lagoas aeradas). Não obstante as

\begin{tabular}{|c|c|c|c}
\multirow{2}{*}{ LOCAL } & QUANTIDADE & $\begin{array}{l}\text { TEOR DE } \\
\text { SÓLIDOS }\end{array}$ & QUANTIDADE \\
\cline { 2 - 4 } & ton/ano & $\%$ & ton MS/ano \\
\hline Distrito Federal & 24.966 & 15,0 & 3.745 \\
\hline São Paulo (Franca) & 16.400 & 27,5 & 4.510 \\
\hline São Paulo (Jundiaí) & 21.900 & 18,0 & 3.942 \\
\hline Rio Grande do Sul (Santa Maria) & 4.745 & 20,0 & 949 \\
\hline Paraná & 26.400 & 30,0 & 7.920 \\
\hline TOTAL & 94.411 & & 21.066 \\
\hline
\end{tabular}

Tabela 1- Quantidade atual de lodos utilizados para fins agrícolas no Brasil 
inúmeras vantagens apresentadas por essa prática em relação às demais formas de destinação final, seu emprego no território nacional, quando comparado a outros países nortes americanos e europeus, pode ser considerado incipiente. Mais informações sobre a quantidade de lodo utilizada na agricultura no Brasil podem ser obtidas na Tabela 1 .

Até o ano de 2006, o arcabouço normativo e legal referente à aplicação agrícola de lodo de estações de tratamento de esgotos sanitários limitava-se às normas técnicas da Companhia de Saneamento Ambiental do Estado de São Paulo - CETESB e do Instituto Ambiental do Paraná IAP. A primeira - P4.230 ago/99 (SÃO PAULO, 1999), basicamente uma cópia do Registro Federal 40 CFR Part 503 - Appendix B (USEPA, 1993) e a segunda - Instrução Técnica CEP/DTA n. 001/2002 (PARANÁ, 2002), baseada principalmente nos estudos e pesquisas desenvolvidos pelo Programa Interdisciplinar de Pesquisa sobre Uso Agrícola de Lodo - PR. A Resolução CONAMA $\mathrm{n}^{\circ} 375$ /2006, doravante referida apenas como Resolução Conama 375 (BRASIL, 2006), promulgada em 29 de agosto de 2006, definiu, em âmbito Federal, critérios e procedimentos para o uso agrícola do lodo de esgotos gerados em estações de tratamento, constituindo assim elemento fundamental e indispensável para a promoção e regulamentação desta prática no território nacional. Entretanto, alguns aspectos dessa regulamentação necessitam ser mais bem discutidos e eventualmente alterados, complementados ou ajustados, de modo a permitir que a mesma atenda efetivamente aos propósitos almejados.

Utilização agrícola do biossólido produzido em estações de tratamento de esgotos sanitários: apenas mais uma opção de destinação final ou uma prática que efetivamente queremos viabilizar?

Quando avaliamos o uso agrícola de biossólidos, uma questão primordial que deve ser respondida é: essa é mais uma opção de destinação final de resíduos ou uma prática de reciclagem que efetivamente almejamos?

A resposta a este questionamento requer uma avaliação mais global sobre os processos de produção e destinação final do resíduo sólido gerado nos diversos processos e operações utilizadas no tratamento de águas residuárias.

A elaboração de projetos e planejamento das ações neste campo continua sendo abordada de forma simplificada e pouco abrangente, absolutamente incompatível com a importância e complexidade características da problemática em questão. Persiste, ainda, a visão na qual a quantidade e qualidade dos resíduos gerados é apenas uma conseqüência dos processos e operações adotados e não algo que se pretenda controlar. Tal fato vem contribuindo substancialmente para o aumento gradativo do volume e periculosidade dos resíduos produzidos e, consequentemente, dos custos dos serviços prestados para o seu condicionamento e destinação final.

Por outro lado, observa-se, mesmo que ainda timidamente, a ocorrência de mudanças do paradigma atual mediante o estabelecimento de novos princípios norteadores. Segundo estes novos princípios, a geração de resíduos gerados passa a ser entendida não como fato inevitável ou inerente, mas sim como consequência de ineficiência do processo produtivo.

Cresce a preocupação e esforço para adoção de medidas preventivas, geralmente tomadas dentro do processo de produção, que possibilitem a não geração ou, pelo menos, minimização da quantidade e periculosidade de resíduos produzidos. Na impossibilidade de eliminá-los por completo, o material resultante deverá ser reciclado, preferencialmente dentro do processo produtivo. Só em último caso, dever-se á pensar no tratamento e destino final (Figura 1).

Normalmente, o processo tradicional utilizado pelas companhias de saneamento para definição das soluções de processamento e destinação final de lodos é efetuado em duas etapas. Primeiro, avalia-se de forma teórica, ou mediante a execução de testes experimentais, a quantidade e qualidade do lodo produzido e, a partir destes dados, efetuam-se estudos de aspectos técnicos, econômicos e ambientais das alternativas possíveis de serem utilizadas para o condicionamento e destinação final do resíduo.

Porém, esse método tradicional vem sendo cada vez mais questionado. Atualmente, os estudos de concepção de projeto da fase sólidas de estações de tratamento de esgoto incluem uma etapa intermediária de avaliação ampla do processso, sob a ótica da produção mais limpa. Nessa etapa, procura-se, principalmente, analisar quais medidas poderiam ser implementadas visando a redução da quantidade e a melhoria da qualidade do resíduo. Essa avaliação, geralmente, 


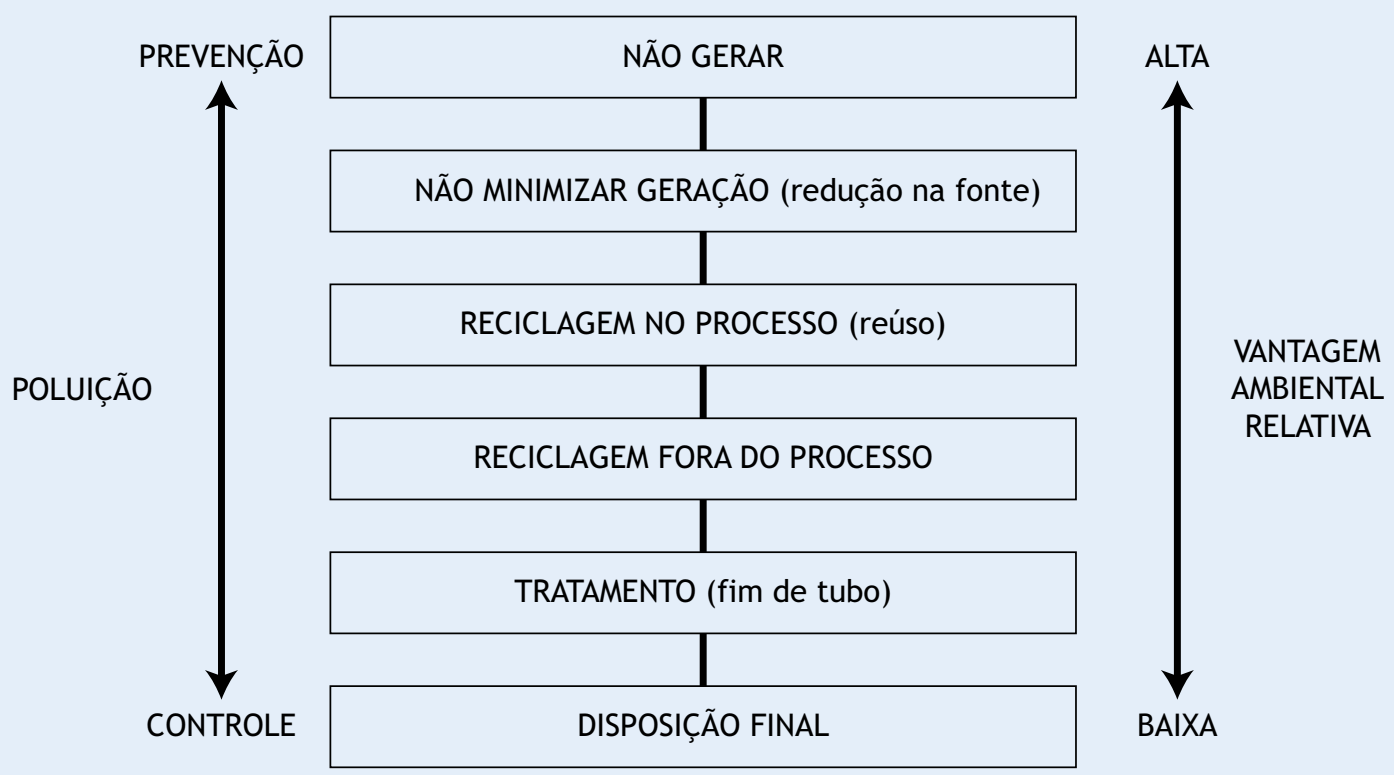

Figura 1- Hierarquização do Gerenciamento de Resíduos

\section{MÉTODO TRADICIONAL}

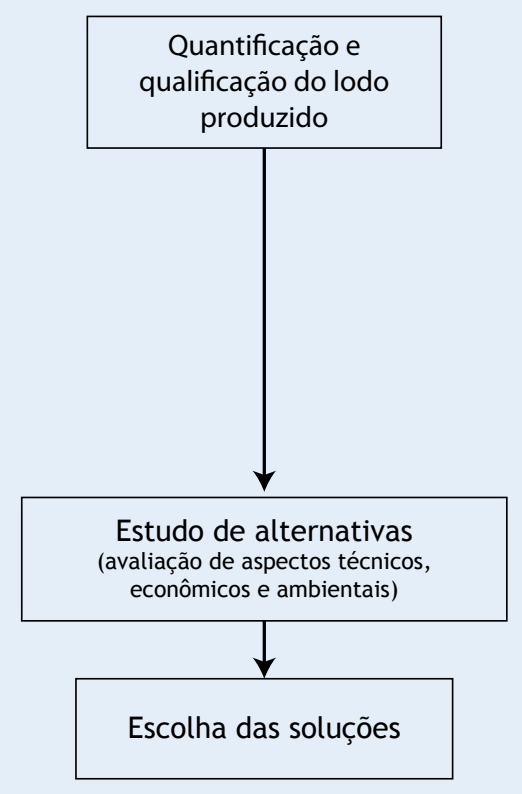

\section{MÉTODO PROPOSTO}

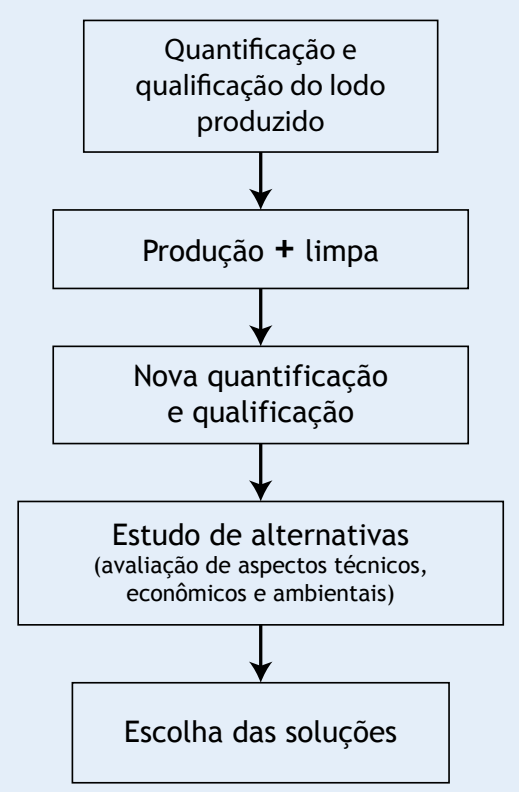

Figura 2- Estratégias para Definições das Soluções para Processamento e Destino Final de Lodos de ETEs 
resulta em nova estimativa quali-quantitativa do lodo gerado, que é utilizada posteriormente para o estudo de alternativas (Figura 2).

Há cerca de uma década, nos países desenvolvidos, se intensificou a preocupação com o processamento e destinação final de resíduos resultantes do tratamento de esgotos sanitários, como consequência do aumento das restrições legais para sua destinação em aterros sanitários. O aumento crescente dos custos operacionais e de implantação dos aterros, bem como a escassez cada vez maior de áreas disponíveis para sua implantação, levou a realização de diversos estudos de avaliação técnica e econômica de usos alternativos que não acarretassem prejuízo à saúde pública e ao meio ambiente. Tais alternativas receberam a denominação de "usos benéficos".

Dentre os usos benéficos do lodo de ETEs, destaque especial deve ser dado à disposição agrícola-florestal, visto possibilitar a necessária reciclagem dos nutrientes nele contidos.

Dos principais nutrientes utilizados em culturas agrícolas, o fósforo é, sem dúvida, aquele cuja reciclagem assume importância destacada, tendo em vista representar cerca de $1 \%$ do dispêndio atual mundial em matéria prima e pelo fato de sua obtenção ser restrita exclusivamente à exploração de jazidas de rochas fosfáticas. Estudos revelam que as reservas mundiais de fósforo hoje conhecidas são capazes de suprir o consumo atual deste elemento por mais que 90 anos (CRAIG; DAVID; BRIAN, 1996). Mesmo para o mais cético dos ambientalistas, este período pode ser estendido, no máximo, para 180 anos, caso se confirme e torne viável a exploração da recente descoberta de crostas e nódulos fosfáticos na plataforma continental da Flórida (LOMBORG, 2002).

O fósforo contido nos biossólidos produzidos nas estações de tratamento de esgoto provém do próprio esgoto (matéria orgânica ou inorgânica, dissolvida ou particulada) e da matéria orgânica constituinte da biomassa aeróbia e/ou anaeróbia gerada nos processos de tratamento. O conteúdo de fósforo no lodo de esgoto sanitário pode variar consideravelmente de estação para estação, em função do tipo de tratamento utilizado e das características qualitativas do esgoto afluente. Nas ETEs apresentadas na Tabela 2 o teor deste elemento variou de 0,6 \% a 3,7 \%. Estima-se que tais valores poderão aumentar significativamente devido à necessidade futura de adequação dos lançamentos de efluentes às exigências ambientais, mediante a implantação de processos terciários de tratamento (remoção de nutrientes).

\begin{tabular}{|c|c|c|c|c|c|c|c|c|c|}
\hline Parâmetro & $\begin{array}{c}\text { ETE } \\
\text { Barueri } \\
\text { (Barueri-SP) }\end{array}$ & $\begin{array}{c}\text { ETE } \\
\text { Franca } \\
\text { (Franca-SP) }\end{array}$ & $\begin{array}{c}\text { ETE } \\
\text { Suzano } \\
\text { (Suzano-SP) }\end{array}$ & $\begin{array}{c}\text { ETE } \\
\text { Lavapés } \\
\text { (SJ Campos-SP) }\end{array}$ & $\begin{array}{c}\text { ETE } \\
\text { Bertioga } \\
\text { (Bertioga-SP) }\end{array}$ & $\begin{array}{c}\text { ETE } \\
\text { Humaitá } \\
\text { (S. Vicente-SP) }\end{array}$ & $\begin{array}{c}\text { ETE } \\
\text { Bichoró } \\
\text { (Mongaguá-SP) }\end{array}$ & $\begin{array}{c}\text { ETE } \\
\text { Brasília } \\
\text { (Brasília-DF) }\end{array}$ & $\begin{array}{c}\text { ETE } \\
\text { Belém } \\
\text { (Curitiba-PR) }\end{array}$ \\
\hline $\begin{array}{l}\text { Nitrogênio } \\
\text { total (\%) }\end{array}$ & 2,25 & 5,53 & 2,31 & 4,5 & 3,93 & 4,10 & 4,84 & 5,5 & 4,91 \\
\hline Fósforo (\%) & 1,48 & 0,93 & 2,65 & 2,59 & 2,60 & 0,6 & 2,89 & 3,0 & 3,70 \\
\hline Potássio (\%) & 0,01 & 0,26 & 0,10 & 0,39 & 0,35 & 0,15 & 0,10 & 0,35 & 0,36 \\
\hline $\begin{array}{l}\text { Matéria } \\
\text { orgânica (\%) }\end{array}$ & 44 & 65,2 & 41 & 52,6 & 68,3 & 63,43 & 71,35 & 52,5 & 69,4 \\
\hline
\end{tabular}

Valores em porcentagem (base seca) / Fonte: (TSUTIYA, 2001)

Tabela 2 - Principais parâmetros de valor agronômico em lodos produzidos em diversas ETEs do Brasil 
O nitrogênio constitui também um elemento essencial para a produção agrícola e atualmente é responsável por aproximadamente $6 \%$ dos gastos em insumos agrícolas (CRAIG; DAVID; BRIAN, 1996). Ao contrário do fósforo, este elemento é abundante no planeta, representando $78 \%$ da composição dos gases constituintes da atmosfera. Apesar de sua alta disponibilidade, grande preocupação vem sendo dada à sua reciclagem, visto a produção de fertilizantes nitrogenados ser efetuada basicamente pela sintetização do $\mathrm{N}_{2}$ do ar, produção esta que exige grande dispêndio energético. Estima-se que a sintetização de 1 $\mathrm{kg}$ de nitrogênio do ar exija cerca de 12,5 kWh (COHIM et al, 2009).

Para contornar esse problema, grandes esforços estão sendo empreendidos no sentido de viabilizar a reciclagem deste elemento nos sistemas de esgotamento sanitário como, por exemplo, a separação dos sistemas de coleta dos dejetos de urina e fezes (COHIM, et al, 2009). Tais sistemas separadores, que já estão sendo efetivamente implantados nos países nórdicos, permitem que os compostos nitrogenados, presentes em grande quantidade na urina, possam ser reciclados de forma mais fácil e segura.

Entretanto, é a partir da estação de tratamento onde se concentram os maiores esforços para a reciclagem do nitrogênio presente no esgoto sanitário, principalmente através do condiciona- mento e disposição agrícola do lodo produzido. Os dados apresentados na Tabela 2 mostram que o teor de nitrogênio no biossólidos das estações de tratamento avaliadas variou de $2,2 \%$ a $5,5 \%$, constituindo assim o macro nutriente presente em maior quantidade neste material.

O potássio é também importante macronutriente agrícola, representando atualmente cerca de $0,1 \%$ dos gastos mundiais em insumos agrícolas. É considerado o oitavo elemento mais abundante na crosta da terra, e estima-se que as reservas existentes possam suprir o consumo nos níveis atuais por aproximadamente 357 anos. Se considerarmos as reservas acessíveis totais, este período pode ser elevado por mais de 700 anos. Tal fato, associado ao baixo teor desse elemento no lodo de esgoto (variando de $0,01 \%$ a $0,36 \%$ - Tabela 2), faz com que pouca preocupação seja dirigida à sua reciclagem nas estações de tratamento.

Devem-se ressaltar também os benefícios econômicos auferidos pela reciclagem dos nutrientes e matéria orgânica do lodo. Estudos desenvolvidos pela SANEPAR (CORRÊA; CORRÊA, 2001) sugerem que apenas o nitrogênio, fósforo e a matéria orgânica presentes em uma tonelada de lodo fresco de esgoto possam representar valor da ordem de $\mathrm{R} \$ 22,00$. Para o lodo seco termicamente, este valor se eleva para $R \$ 158,60$ (Tabela 3)

\begin{tabular}{|c|c|c|c|c|c|}
\hline Parâmetros & Lodo Fresco & $\begin{array}{c}\text { Lodo } \\
\text { Compostado }\end{array}$ & $\begin{array}{l}\text { Lodo } \\
\text { Caleado }\end{array}$ & $\begin{array}{l}\text { Lodo } \\
\text { Irradiado }\end{array}$ & Lodo Seco a Calor \\
\hline Nitrogênio & $\mathrm{R} \$ 7,70$ & $\mathrm{R} \$ 10,90$ & $\mathrm{R} \$ 10,10$ & $\mathrm{R} \$ 11,00$ & $\mathrm{R} \$ 57,50$ \\
\hline Fósforo & $\mathrm{R} \$ 12,50$ & $\mathrm{R} \$ 14,00$ & $R \$ 20,00$ & $R \$ 16,30$ & $\mathrm{R} \$ 87,70$ \\
\hline Matéria Orgânica & $\mathrm{R} \$ 1,80$ & $R \$ 6,30$ & $\mathrm{R} \$ 2,00$ & $\mathrm{R} \$ 2,50$ & $\mathrm{R} \$ 13,40$ \\
\hline $\mathrm{CaCO}_{3}$ & $\mathrm{R} \$ 0,0$ & $\mathrm{R} \$ 0,0$ & $\mathrm{R} \$ 9,10$ & $\mathrm{R} \$ 0,0$ & $\mathrm{R} \$ 0,0$ \\
\hline Total & $\mathrm{R} \$ 22,00$ & $\mathrm{R} \$ 31,20$ & $R \$ 41,20$ & $R \$ 29,80$ & $\mathrm{R} \$ 158,60$ \\
\hline
\end{tabular}

Fonte (CORREA; CORREA, 2001) 
Pelos aspectos analisados, parece que a resposta ao questionamento inicialmente formulado não pode ser outra senão a afirmativa: SIM

Contudo, apesar dos inúmeros benefícios anteriormente apresentados, esta prática ainda vem sendo bastante questionada, inclusive por parte da comunidade técnica especializada.

Alguns, por total desconhecimento, acreditam que tal destinação é uma forma encontrada pelas companhias operadoras para contornar as exigências características de alternativas pretensamente mais atrativas do ponto de vista ambiental (aterro sanitário, por exemplo), visando exclusivamente redução de custos e maior facilidade de implantação. Ledo engano; todos aqueles que já operaram sistemas de tratamento de águas residuárias sabem perfeitamente que não existe nada mais cômodo e simples do que encaminhar o lodo produzido por uma estação de tratamento para aterro, pois requer apenas a viabilização de contratos com empresas operadoras de aterro e de carregamento e transporte do material. Tais contratos são de fácil fiscalização e apresentam, muitas vezes, custo inferior aos associados à disposição agrícola.

Assim, não seria exagero afirmar que, à primeira vista, não existe nada mais atrativo para o gerente de uma estação de tratamento do que a opção pela destinação em aterro, cujos aspectos logísticos são bem mais simples do que os relativos ao uso agrícola. $\mathrm{O}$ que verdadeiramente leva as companhias a esta prática é a sua sustentabilidade ambiental.

As vantagens do uso agrícola dos biossólidos produzidos em estações de tratamento de esgotos sanitários estão claramente expressas em três dos "considerandos" da Resolução CONAMA 375, apresentados a seguir:

- Considerando que o lodo de esgoto sanitário constitui fonte de matéria orgânica e de nutrientes para as plantas e que sua aplicação no solo pode trazer benefícios à agricultura

- Considerando que o uso agrícola do lodo de esgoto é uma alternativa que apresenta vantagens ambientais quando comparado a outras práticas de destinação final

- Considerando que a aplicação de lodo de esgoto na agricultura se enquadra nos princípios de utilização de resíduos de forma ambientalmente adequada

Fica claro, portanto, que a referida Resolução tem como princípio básico a viabilização da apli- cação agrícola do lodo, evidentemente de forma a não ocasionar efeitos deletérios ao meio ambiente e à saúde pública.

\section{Logística relacionada ao gerenciamento do uso agrícola do lodo}

Comparada às outras alternativas de disposição final, a aplicação do lodo de esgoto para fins agrícolas requer uma logística substancialmente mais complexa e bastante diferenciada daquelas comumente empregadas pelas companhias de saneamento na rotina operacional de estações de tratamento de esgotos sanitários. Tal logística envolve aspectos relacionados ao monitoramento do material, seleção de áreas, transporte e aplicação do material, elaboração de projetos agronômicos, registros detalhados que permitam o rastreamento dos lotes aplicados, dentre outros.

Das questões de ordem logística, a de maior complexidade é, sem dúvida, a viabilização de áreas agrícolas que possam receber, sem grandes interrupções, o lodo produzido pelas estações de tratamento.

A compatibilização da produção de lodo e sua aplicação no solo devem levar em consideração as características inerentes ao processo de adubação de culturas agrícolas, normalmente sujeito a períodos sazonais de descontinuidade. Somam-se a isto, as imposições da regulamentação em vigor - Resolução CONAMA 375, que, em sua Seção IV, artigo 12, define uma série de restrições de períodos de tempo a serem respeitados entre duas aplicações sucessivas. Esses são aspectos particularmente importantes em grandes plantas, onde se tornaria economicamente inviável a implantação de pátios de estocagem com área disponível suficiente para acumulação do grande volume de lodo gerado entre aplicações subsequentes.

A Resolução CONAMA 375 define que a aplicação do lodo de esgoto e produtos derivados só poderá ocorrer mediante a existência de uma Unidade de Gerenciamento de Lodo - UGL, que deverá ser devidamente licenciada pelo órgão ambiental, segundo os mesmos procedimentos adotados para outras fontes de poluição. Estipula também que o licenciamento deverá obrigatoriamente contemplar uma avaliação geral das possíveis áreas de aplicação existentes próximas à UGL. Em nenhum momento, é citada a necessidade de licenciamento individual das áreas junto 
ao órgão competente. Tal fato foi muito discutido durante as reuniões do Grupo Técnico - GT encarregado pela elaboração da proposta de Resolução e entendeu-se que a aprovação prévia das áreas inviabilizaria, do ponto de vista logístico, a gestão da aplicação agrícola do lodo.

Cabe, entretanto, ressaltar que, segundo o artigo 16 da Resolução CONAMA 375, toda aplicação deverá ser condicionada à elaboração de projeto agronômico para as áreas de aplicação, firmado por profissional devidamente habilitado. Tal projeto deverá seguir o roteiro constante no Anexo VIII da Resolução e ficará disponível para eventuais avaliações do órgão fiscalizador competente.

O transporte também constitui importante aspecto relacionado ao gerenciamento da utilização agrícola do lodo, visto representar o item de maior custo operacional dessa prática.

Muitas vezes as dificuldades de se encontrar áreas aptas e disponíveis para uso agrícola do lodo levam à necessidade de executar longos trajetos. No Estado de São Paulo, algumas aplicações são realizadas em áreas situadas cerca de 170 quilômetros distantes do local de produção. Não se pode dizer que exista uma distância máxima que inviabilize economicamente o transporte, pois a mesma depende de uma série de outros fatores, dentre os quais a existência e tipo de estrada de acesso, quantidade e preço de pedágios no percurso, a possibilidade de frete para retorno do caminhão até o local da estação, etc...

Normalmente, o custo deste item está relacionado à massa ou volume transportado e à quilometragem percorrida ( $\mathrm{R} \$$ por tonelada ou metro cúbico por quilômetro), muito embora outros fatores possam desempenhar papel relevante em sua composição. Em plantas localizadas em grandes cidades ou regiões metropolitanas, cujas rotas de saída e acesso estão quase sempre sujeitas a tráfego intenso, o custo do transporte pode estar muito mais relacionado ao tempo gasto no percurso do que à quilometragem percorrida. Recomenda-se assim que, nestes casos, o tempo gasto no percurso de entrada e saída de grandes cidades seja igualmente considerado na composição do custo de transporte do lodo até o seu destino final.

A Resolução CONAMA 375 apresenta, em seu Anexo VII, recomendações quanto ao transporte dos biossólidos, não havendo, a nosso ver, maiores dificuldades das companhias de saneamento em cumpri-las. É importante, porém, ressaltar que a Lei Estadual de São Paulo n 12.300, que institui a Política Estadual de Resíduos Sólidos estabelece, no seu artigo 32, as responsabilidades do gerador do resíduo. Segundo essa lei, compete ao gerador do resíduo sólido a responsabilidade pelo seu gerenciamento, desde a geração até a destinação final, incluindo o transporte interno e externo, mesmo que estas sejam eventualmente executadas por terceiros. Não basta assim que as companhias de saneamento exijam, apenas na contratação, o comprometimento de seus prestadores de serviços com relação às normas e procedimentos de segurança necessários para minimizar riscos de ocorrência de derramamentos dos resíduos durante o trajeto, mas também devem se certificar que estas estejam sendo efetivamente cumpridas.

Considerações sobre os limites de parâmetros químicos e microbiológicos fixados pela Resolução CONAMA 375

A Resolução CONAMA 375, em seu artigo 7, estabelece que a caracterização do lodo de esgoto ou produto derivado a ser aplicado deve incluir substâncias inorgânicas e orgânicas potencialmente tóxica, organismos patogênicos e indicadores da qualidade bacteriológica do biossólido.

\section{Substâncias Inorgânicas}

A maiores preocupações quanto à presença de elementos e substâncias inorgânicas no biossólido restringe-se, basicamente, à presença de metais e metalóides, tendo em vista os problemas que estes podem ocasionar às culturas, organismos do solo, seres humanos e outros animais.

Duas metodologias consagradas em nível mundial podem ser distinguidas com relação ao acúmulo de metais e metalóides no lodo e no solo: a européia, denominada "impacto zero" e a norte americana, que utiliza a análise de risco.

A metodologia européia do "impacto zero", também chamada de "balanço de metal", se baseia na assunção de que a quantidade de metais que pode ser adicionada ao solo não deve ser superior àquela que dele é removida pelos processos naturais, tais como remoção pelas culturas agrícolas, erosão do solo e lixiviação. O principal objetivo da proposição dessa metodologia é o de preservar o solo e outros recursos naturais para futuras gerações no estado atual em que se encontra, possibilitando ser utilizado para qualquer 
finalidade (BERTON, 2000).

A metodologia adotada pela Agência Ambiental dos Estados Unidos (USEPA 40 CRF part 503) é baseada em avaliação de risco através de 14 rotas de exposição, preestabelecidas para metais e metalóides após sua incorporação ao solo agrícola. A legislação "Standard for the Use or Disposal of Sewage Sludge" ( Code of Federal Regulation, Title 40, Part 503), desenvolvida pela U. S. Environmental Protection Agency, foi publicada em 1993. Este documento foi objeto de uma grande revisão efetuada em 2002, sendo mantidos todos os parâmetros definidos na versão original, pois não foram encontradas evidências científicas de que estes não eram adequados à proteção da saúde pública e meio ambiente (WEF HIGHLIGHTS, 2002).

Chang et al (2002), no relatório preparado para a Organização Mundial de Saúde - "Developing Human Health related Chemical Guideli- nes for Water and Sewage Sludge Applications in Agriculture", comentam que ambas as metodologias são válidas e, devido às diferenças de filosofia e finalidades, resultam em limites com valores numéricos bastante díspares, podendo levar à considerações equivocadas. Na realidade, com a utilização da metodologia "impacto zero", o limite máximo de concentração de substâncias químicas inorgânicas (metais e metalóides) dos países da Europa representa o nível de carga máximo de modo a evitar o acúmulo, enquanto que os valores fixados na legislação Americana visam basicamente à prevenção de efeitos nocivos à saúde pública, plantas e outros animais. Ambos critérios são conceitualmente defensáveis, muito embora os autores do referido relatório recomendem, para países em desenvolvimento, a adoção de padrões com base na metodologia da agencia ambiental norte americana - EPA.

A Tabela 4 apresenta os limites máximos de

\begin{tabular}{|c|c|c|c|}
\hline \multirow{2}{*}{ PARÂMETRO } & \multicolumn{3}{|c|}{$\begin{array}{l}\text { Concentração máxima permitida no } \\
\text { biossólido }(\mathrm{mg} / \mathrm{kg} \text {, base seca) }\end{array}$} \\
\hline & $\begin{array}{l}\text { EUA - USEPA } 40 \\
\quad \text { CFR/503 }\end{array}$ & $\begin{array}{l}\text { Comunidade Européia } \\
\text { - Diretiva 86/278 EEC }\end{array}$ & $\begin{array}{l}\text { Brasil - } \\
\text { CONAMA } 375\end{array}$ \\
\hline Arsênio & 41 & - & 41 \\
\hline Bário & - & - & 1300 \\
\hline Cádmio & 39 & $20-40$ & 39 \\
\hline Cobre & 1500 & $1000-1750$ & 1500 \\
\hline Chumbo & 300 & $750-1200$ & 300 \\
\hline Cromio & - & - & 1000 \\
\hline Mercúrio & 17 & $16-25$ & 17 \\
\hline Molibdênio & - & - & 50 \\
\hline Níquel & 420 & $300-400$ & 420 \\
\hline Selênio & 100 & - & 100 \\
\hline Zinco & 2800 & $2500-4000$ & 2800 \\
\hline
\end{tabular}

Tabela 4- Limites de substâncias químicas inorgânicas (metais pesados) para uso agrícola de biossólidos fixados pela regulamentação dos EUA, Comunidade Européia (European Community Council, 1986) e CONAMA 375. 
substâncias químicas inorgânicas (metais e metalóides) permitidos para uso agrícola do biossólido nas legislações americana, européia e brasileira.

Observa-se que, para a fixação da maioria dos parâmetros, a Resolução CONAMA 375 fez uma opção clara pela metodologia de análise de risco proposta pela legislação americana USEPA 40 CRF, Part 503. O mesmo não ocorreu, entretanto, para a limitação de concentração no lodo dos metais crômio, bário e molibdênio, cujos valores se basearam em metodologia proposta pela agência ambiental do Estado de São Paulo - CETESB (DIAS, 2004).

A metodologia adotada pela CETESB propõe que a determinação da concentração máxima de metais pesados no lodo seja fixada mediante a utilização da Equação 1:

$$
C L=\frac{(V A-V R) \times Q S}{T A x A A x T}
$$

\footnotetext{
Onde

$C L=$ concentração no lodo, $\mathrm{mg} / \mathrm{kg}$;

$V A=$ valor de alerta no solo, $\mathrm{mg} / \mathrm{kg}$;

$V R=$ valor de referência no solo, $M G / \mathrm{kg}$;

$Q S$ = Quantidade de solo em 1 Hectare, $2.600 .000 \mathrm{~kg} / \mathrm{ha}$.

(para uma camada arável de 0,2 m e densidade do solo de $\left.1300 \mathrm{~kg} / \mathrm{m}^{3}\right)$;

$T A$ = taxa de aplicação de lodo, fixada em $5.000 \mathrm{~kg} / \mathrm{ha}$;

$A A=$ número de aplicações anuais, fixada em 1 aplicação

por ano;

$T$ = tempo de aplicação em anos, fixada em 50 anos.
}

É bastante difícil encontrar justificativa plausível para utilização de metodologias diferenciadas para fixação da concentração de metais no lodo, como também para a fixação de limites de alguns parâmetros (bário, crômio e molibdênio) para todo território nacional, baseados em valores de referências estabelecidos através de estudos simplificados de caracterização de solos do Estado de São Paulo (SÃO PAULO, 2001). Não cabe aqui fazer qualquer juízo de valor com relação à propriedade e adequação dos limites fixados, mas sim quanto à falta de critério utilizado para sua definição.

\section{Substâncias Orgânicas}

A Resolução CONAMA 375 também exige a caracterização do lodo para substâncias orgânicas potencialmente tóxicas indicadas na tabela 1 do ANEXO V da Resolução: são listadas 34 substâncias que devem ser monitoradas no lodo, sem, entretanto, estabelecer o limite máximo permitido para cada uma delas.

Estudos realizados pela EPA demonstraram que substâncias orgânicas não se encontram em grande quantidade no lodo de esgoto produzido nos Estados Unidos da América e que seus efeitos adversos à saúde pública decorrentes da prática de disposição agrícola não são tão importantes quando comparados com outras fontes de exposição (SMITH, 2001). Sendo assim, tanto a legislação européia, como a norte americana optaram pela não exigência de monitoramento e fixação de limites máximos destas substâncias no lodo.

É, portanto, de se estranhar o fato da regulamentação brasileira definir a obrigatoriedade de monitoramento de substâncias orgânicas sem, contudo, estabelecer os limites máximos permitidos. Caso a razão esteja relacionada à obtenção de dados sobre a presença e concentração destas substâncias no lodo produzido no Brasil, acreditamos que existam formas mais apropriadas para atingir este objetivo, tal como a realização de campanhas de monitoramento, em nível nacional, de lodos oriundos de diversas tipologias de sistemas de esgotamento sanitário. Desta forma, além de possibilitar obtenção de melhor conhecimento sobre o objetivo almejado, evitar-se-ia também que toda e qualquer estação de tratamento de esgoto brasileira fosse obrigada a efetuar, pelo menos uma vez, o monitoramento das concentrações de 34 substâncias orgânicas, cujas determinações analíticas requerem sofisticados métodos laboratoriais (cromatografia, por exemplo) de custos bastante elevados.

\section{Microbiológicos}

A Resolução CONAMA 375 estabelece duas classes de lodo de esgotos, de acordo com suas características microbiológicas.

A Tabela 3 do artigo 11 - seção III define 
para lodo classe A as seguintes concentrações máximas: coliformes termotolerantes: $10^{3}$ $\mathrm{NMP} / \mathrm{g}$ de ST, ovos viáveis de helmintos: 0,25 ovo/g de ST, Salmonella: ausência em $10 \mathrm{~g}$ de ST e vírus: 0,25 UFP ou UFF/g de ST. Para os lodos Classe B, os limites máximos se restringem a coliforme termotolerantes: $10^{6} \mathrm{NMP} / \mathrm{g}$ de ST e ovos viáveis de helmintos: 10 ovos/g de ST.

Os padrões microbiológicos da classe A são exatamente os mesmos dos fixados pela legislação norte americana - USEPA 40 CRF, Part 503, segundo a qual, os lodos enquadrados nesta classe não estão sujeitos a qualquer tipo de restrição para a sua aplicação e comercialização, podendo inclusive ser adquiridos em supermercados para uso doméstico. Entretanto, a Resolução CONAMA 375 estabelece uma série de restrições para o uso de lodo dessa classe, podendo se destacar:

- Proibição do uso em pastagens e cultivo de olerícolas, tubérculos e raízes, e culturas inundadas, como demais culturas cuja parte comestível entre em contato com o solo (Artigo 12)

- Utilização em pastagens em períodos inferiores a 24 meses (art 12 , parágrafo 1)

- Proibição de aplicação em solos que irão ser utilizados para culturas de olerícolas, tubérculos, raízes e demais culturas cuja superfície entre em contato com o solo bem como cultivos inundáveis, em períodos inferiores a 48 meses (artigo 12, parágrafo 2)

Não encontramos razão para o estabelecimento de tais restrições, muito menos qualquer estudo técnico-científico que as justifiquem.

Por outro lado, a Norma 503 permite que a ausência de patógenos (vírus e helmintos) pode ser comprovada pelo monitoramento desses microrganismos "ou" de variáveis de controle operacional dos processos de redução adicional de patógenos - PRAP , enquanto que CONAMA 375 estabelece a necessidade de monitoramento de ambos. Além disso, a regulamentação norte americana estabelece que biossólidos classe A devem apresentar menos que 1000 Cter/g ST "ou" menos de 3 salmonelas/4 g ST (limite de decção), e a CONAMA 375/2006 essa alternativa é traduzida como "e". Com relação a essa questão, o estudo crítico-comparativo sobre as regulamentações brasileira, estadunidense e britânica de qualidade microbiológica de biossólidos para uso agrícola realizada por Rafael K. X, Bastos, Paula Dias Bevilacqua e David Duncan Mara (Bastos R.K.X. et al, 2013) afirma:

"A categoria brasileira Classe A claramente reproduz a dos EUA, porém apresenta alguns aspectos mais rigorosos ..., a abordagem brasileira parece ignorar o fato de que monitoramento de rotina para patógenos não é prática viável, além de desconsiderar o próprio conceito de organismos indicadores e a utilidade de variáveis de controle operacional (incorporados nos procedimentos de APPCC no Reino Unido. "

Os limites microbiológicos previstos para a classe B foram definidos pela Environmental Protection Agency - EPA a partir da característica média da densidade de coliformes termotolerantes de lodos de esgotos produzidos nos Estados Unidos em estações que utilizavam, na fase sólida, digestores anaeróbios de média taxa. Nos estudos desenvolvidos anteriormente à promulgação dessa norma, a média de concentração deste indicador foi de $2 \times 10^{6}$ $\mathrm{NMP} / \mathrm{g}$ de ST e, por este motivo, esse valor foi fixado como limite máximo tentativo. A partir daí, a aplicação agrícola do lodo foi acompanhada por estudos epidemiológicos para avaliar eventuais problemas à saúde pública da população exposta a esta prática (população situada no entorno de áreas de aplicação, trabalhadores encarregados pela aplicação, manuseio, transporte e comercialização e consumidores dos produtos de culturas que receberam aplicações de biossólidos). Visto que estes estudos não estabelecem "nexo causal" entre a aplicação de lodo de esgoto com estas características e aumento da morbimortalidade na população exposta, optou-se pela manutenção do referido padrão (NATIONAL RESEARCH COUNCIL, 1996).

Os mesmos procedimentos foram utilizados para o estabelecimento dos padrões microbiológicos do lodo classe B no Reino Unido. Esta Resolução, entretanto, fixou o limite máximo para coliformes termotolerantes em $10^{6}$ $\mathrm{NMP} / \mathrm{g}$ de ST, devido ao fato de que os estudos de caracterização de lodo estabilizado produzidos nas estações de esgoto naquele país apresentarem valores médios dessa ordem de grandeza.

A Resolução CONAMA 375 não realizou os se 
baseou em qualquer estudo de caracterização do lodo digerido produzido no Brasil, optando simplesmente pela utilização do padrão estabelecido na regulamentação do Reino Unido.

Tanto a regulamentação norte americana como inglesa não fixaram limites máximos para concentração de ovos de helmintos viáveis para a classe $B$, muito embora tenha sido evidenciada a presença destes organismos neste material. Entendeu-se que a aplicação de lodo classe B, desde que respeitadas as restrições impostas para sua utilização (uso de equipamentos individuais ou coletivos de proteção, incorporação ao solo, tipo de cultura, etc.), não representa risco significativo para o aumento da incidência de helmintoses na população exposta.

A Resolução CONAMA 375, mesmo não estando baseada em qualquer tipo de caracterização, estudo epidemiológico ou análise de risco com relação a ovos de helmintos e em discordância com os padrões estabelecidos em várias regulamentações vigentes no cenário internacionais para lodos classe $\mathrm{B}$, optou pela fixação deste parâmetro em 10 ovos/g de ST. Estranha-nos sobremaneira não somente a fixação do limite, mas principalmente o valor estabelecido, visto não existir qualquer trabalho técnico-científico que o justifique.

Ressalta-se ainda, que a regulamentação brasileira estabelece, ao contrário das do Reino Unido e EUA, a proibição de aplicação de biosssólidos classe B em culturas alimentícias e pastagens, Com relação a esse aspecto, o estudo desenvolvido por Rafael et colaboradores (Bastos R.K.X. et al, 2013) afirma:

"Em relação às restrições para os diferentes usos de biossólidos Classe $\mathrm{B}$, as condições climáticas brasileiras são, comparadas às dos EUA e do Reino Unido, em tese e em geral, menos favoráveis à sobrevivência de patógenos, mas, ainda assim, a Resolução CONAMA $357 / 2006$ estabelece critérios muito mais restritivos, ao ponto de proibir a aplicação em culturas alimentícias e pastagens. Mais uma vez, a abordagem brasileira aparenta ser extremamente conservadora..."

\section{Considerações finais}

O uso agrícola do lodo produzido em estações de tratamento de esgotos sanitários é uma alternativa que apresenta vantagens am- bientais quando comparada a outras práticas de destinação final deste material. Destaque especial deve ser dado ao fato dessa prática propiciar a necessária reciclagem de nutrientes, cuja importância vem crescendo consideravelmente nos últimos anos devido à previsão de aumento de demanda e de escassez futura desses elementos.

Ao contrário do que pensam alguns, as razões que levam as companhias de saneamento a optarem por essa alternativa de destinação final do lodo, não estão relacionadas à simplicidade logística de gestão ou custo reduzido de sua implantação, mas sim às suas características de sustentabildade.

Mesmo reconhecendo constituir um grande avanço na promoção e regulamentação do uso agrícola dos lodos produzidos em estações de tratamento de esgotos sanitários no território nacional, a Resolução CONAMA 375 apresenta aspectos que necessitam ser mais bem discutidos e, eventualmente, alterados, complementados ou ajustados, de modo a permitir atender efetivamente aos propósitos almejados. Para tanto, consideramos imprescindível a constituição de um grupo de trabalho visando promover sua revisão.

\section{Referências}

BASTOS, R. K. X. ; BEVILACQUA, Paula Dias ; MARA, D. D. Análise critico-comparativa das regulamentações brasileira, estadunidense e britânica de qualidade microbiológica de biossólidos para uso agrícola. Revista DAE, v. 191, p. 10-20, 2013. HYPERLINK "http://lattes. cnpq.br/5178732442154229”

BERTON, R. S. Riscos de contaminação do agroecosistema com metais pesados. In : Impacto Ambiental do Uso Agrícola do Lodo de Esgoto. Ed. Bettiol, W.; Camargo, O. A. Jaguariúna, EMBRAPA Meio Ambiente, 2000.

BRASIL. CONSELHO NACIONAL DO MEIO AMBIENTE. CONAMA. Define critérios e procedimentos, para o uso agrícola de lodos de esgoto gerados em estações de tratamento de esgoto sanitário e seus produtos derivados, e dá outras providências. Resolução 375, de 29 de agosto de 2.006. Diário Oficial da República Federativa do Brasil. 2006.

CHANG, A. C. et al. Developing Human Health- 
-related Chemical Guidelines for Reclaimed Water and Sewage Sludge Applications in Agriculture. World Health Organization. May, 2002.

COHIM, E. ; ASHER, K. Sistemas de esgotamento sanitário : conhecer o passado para moldar o futuro. In : CONGRESSO BRASILEIRO DE ENGENHARIA SANITÁRIA E AMBIENTAL, 24. , 2007, Belo Horizonte/ MG. Anais ... Rio de Janeiro : ABES - Associação Brasileira de Engenharia Sanitária e Ambiental, 2007. v. 2, p. 1-11.

COHIM, E. et al. Uso Racional de Água e Energia : Conservação de água e energia em sistemas prediais e públicos de abastecimento de água. In : GONÇALVES, R. F. (coordenador) . Perspectivas futuras : água, energia e nutrientes, 1. Ed. Rio de Janeiro : ABES, 2009. p. 296348.

CORRÊA, R. S.; CORRÊA, A. S. Valoração de biossólidos como fertilizantes e condicionantes de solos. SANARE (Revista Técnica da SANEPAR), v. 16, n. 2, p. 49-56, 2001.

CRAIG, J. R. ; DAVID, J. V. and BRIAN, J. S. Resources of Earth: Origin, Use and Environmental Impact. Upper Saddle River, NJ: Prentice Hall, 1996.

DIAS, C. L. Estabelecimento de Valores de Alerta e Limites Máximos no Lodo de Esgoto. Relatório técnico interno - CETESB, outubro de 2004.

EUROPEN COMUNITY COUNCIL directive on the protection of the environmental and in particular of the soil when sewage sludge is used in agriculture. Official Journal Euro. Comon L. 187/6. 1986.

LOMBORG, B. O Ambientalista Cético: A Real Situação do Mundo - Rio de Janeiro : Elsevier, 2002.

NRC - NATIONAL RESEARCH COUNCIL. Committee on The Use of Treated Municipal Wastewater Effluents and Sludge in the Production of Crops for Human Consumption. 1996 , 176 p.

PARANÁ (Estado). Secretaria de Estado do Meio Ambiente e Recursos Hídricos. Instituto Ambiental do Paraná. Instrução Técnica CEP/ DTA N. 001/2002. Dispõe sobre a utilização agrícola de lodo de estação de tratamento de esgoto sanitário. Curitiba, 07 de maio de 2002.

SAMPAIO, A. O; GONÇALVES, M. C. Custos operacionais de estações de tratamento de esgoto por lodos ativados : estudo de caso ETE - Barueri. In : In : CONGRESSO BRASILEIRO DE ENGENHARIA SANITÁRIA E AMBIENTAL, 20. , 1999, Rio de Janeiro/RJ. Anais ... Rio de Janeiro : ABES - Associação Brasileira de Engenharia Sanitária e Ambiental,1999, p. 676685.

SÃO PAULO (Estado). CETESB. Aplicação de lodos de Sistemas de Tratamento Biológico em Áreas Agrícolas - Critérios para Projeto e Operação (Manual Técnico). P 4.320. Águas Subterrâneas. Companhia de Tecnologia de Saneamento ambiental, São Paulo, 1999.

SÃO PAULO (Estado). CETESB. Relatório de Estabelecimento de Valores Orientadores para Solos e Águas Subterrâneas. Companhia de Tecnologia de Saneamento ambiental, São Paulo, 2001.

SMITH, S. R. Are controls on organics contaminants necessary to protect the environment when sewage sludge is used in agriculture ? Prog. In Environ. , v. 2 , p. 129-146, 2000.

TSUTIYA, M. T. Características de biossólidos gerados em estações de tratamento de esgotos. In : (Org.) Biossólidos na Agricultura, 1. Ed. São Paulo : Sabesp, 2001. p. 89-131.

USEPA. Standards for the Use and Disposal of Sewage Sludge. Code of Federal Regulation, Title 40, Part 503. U. S. Environmental Protection Agency, 1993.

USEPA, "A plain english guide to the EPA part 503 biosolids rule," Tech. Rep. EPA/832-R-93-003, Office of Wastewater Management, Washington, DC, USA, 1994.

WEF HIGHLIGHTS. Wef Commends NRC's Part 503 Assessment, Call for Continued Research. v. 39, n. 7, July/August, 2002.

\footnotetext{
*Américo de Oliveira Sampaio Engenheiro Civil formado pela Universidade Mackenzie, mestrado na Escola de Engenharia de São Carlos / USP. Superintendente de Pesquisa, Desenvolvimento Tecnológico e Inovação da SABESP.
} 